\title{
Fontan Failure and Thrombosis of Total Cavo-Pulmonary Connection Conduit
}

\author{
Nirmal Panthee, ${ }^{1}$ Arata Murakami, ${ }^{1}$ Masahiko Ando, ${ }^{1}$ Tetsuhiro Takaoka, ${ }^{1}$ Minoru Ono ${ }^{1}$ \\ 'Department of Cardiac Surgery, The University of Tokyo, 7-3-1 Hongo, Bunkyo-ku, Tokyo 1 13-8655, Japan.
}

\section{ABSTRACT}

The immediate postoperative period of Fontan operation is frequently complicated by hemodynamic instability, sometimes requiring fenestration of the conduit. Thrombosis of total cavo-pulmonary connection conduit warrants early intervention to prevent systemic and pulmonary embolism. We report a case of Fontan failure requiring fenestration; which was further complicated by thrombosis of total cavo-pulmonary connection conduit and managed with anticoagulants.

Keywords: congenital heart disease; fontan procedure; thrombosis.

\section{INTRODUCTION}

Fontan procedure is the final common palliative pathway for complex congenital heart diseases. Immediate postoperative course of Fontan procedure is complicated by hemodynamic instability, elevated systemic venous and pulmonary artery pressures, pulmonary edema, and low cardiac output. Creation of fenestration improves cardiac output in patients with low cardiac output. ${ }^{1,2}$

Thromboembolic events, which range from 5.2 to $20 \%$, account for significant morbidity and mortality after Fontan procedure. ${ }^{3-6}$ However, there are no definite guidelines for management of thrombosis of conduit. We report a case of management of Fontan failure requiring fenestration; which was further complicated by thrombosis of conduit.

\section{CASE REPORT}

A one-year-and-seven-month-old girl with double outlet right ventricle (DORV), pulmonary atresia/ ventricular septal defect (PA/VSD), patent ductus arteriosus (PDA), and patent foramen ovale (PFO) underwent staged operations with modified left Blalock Taussig (BT) shunt (age: 35 days), balloon atrial septostomy (age:
45 days), Glenn operation (age: 10 months) and Fontan palliation (age: 19 months). Pre-Fontan catheterization revealed pulmonary artery index (PAI) of $302 \mathrm{~mm}^{2} /$ $\mathrm{m}^{2}$, pulmonary vascular resistance $(R p)$ of $2.51 \mathrm{u} \mathrm{m}^{2}$, central venous pressure (CVP) of $12 \mathrm{mmHg}$ and multiple aorto-pulmonary collaterals (APCs) and veno-venous (VV) collaterals between innominate vein and inferior vena cava (IVC). The APCs were obliterated by coil embolization before Fontan procedure.

She underwent Fontan procedure using extra-cardiac conduit of $18 \mathrm{~mm}$ polytetrafluoroethylene (PTFE) graft under cardiopulmonary bypass. Upon completion of the procedure, transesophageal echocardiography (TEE) revealed higher values of right pulmonary venous return than left with TCPC shunt flow of $0.4 \mathrm{~m} / \mathrm{s}$. CVP increased to $14 \mathrm{mmHg}$ from baseline $12 \mathrm{mmHg}$. With the acceptable CVP and other hemodynamics, we decided not to combine fenestration with the primary operation. She was extubated in the operating room

Correspondence: Dr. Nirmal Panthee, Department of Cardiac Surgery, The University of Tokyo, 7-3-1 Hongo, Bunkyo-ku, Tokyo 113 . 8655, Japan. Email: nipanthee@gmail.com, Phone: +81-80-3306-6744. 
and transferred to PICU. Two hours after arrival to PICU, her hemodynamics deteriorated, CVP increased to $22 \mathrm{mmHg}$ requiring re-intubation and nitric oxide (NO) inhalation at $10-20 p p m$. Both transesophageal and transthoracic echocardiography failed to show major pressure gradient between SVC and IVC. Additionally, direct pressure measurement of IVC through a central line inserted via femoral vein was equal to that of Glenn pressure ruling out obstruction at the level of TCPC conduit. We planned for Fontan revision with creation of direct fenestration $(4 \mathrm{~mm})$ between TCPC conduit and RA; and ASD enlargement on second postoperative day. Post-procedure TEE revealed fenestration flow of $1 \mathrm{~m} / \mathrm{s}$ and ASD flow of $1.5 \mathrm{~m} / \mathrm{s}$. Her CVP fluctuated between 18 and $20 \mathrm{mmHg}$ in the initial few days after fenestration with $\mathrm{PaO} 2$ of $35-38 \mathrm{mmHg}$ on $\mathrm{FiO} 2$ of 1.0, NO inhalation; and oral sildenafil. Five days after fenestration, TEE demonstrated $15 \times 7 \mathrm{~mm}$ thrombus attached to the anterior wall of TCPC conduit (Figure 1). The findings were confirmed by CECT chest (Figure 2) and it was managed conservatively with anticoagulants (warfarin and heparin), aspirin, and dipyridamole. The thrombosis responded well with anticoagulants (Figure 2 ) and she was discharged home on $29^{\text {th }}$ postoperative day with $\mathrm{SpO} 2$ of $82 \%$.

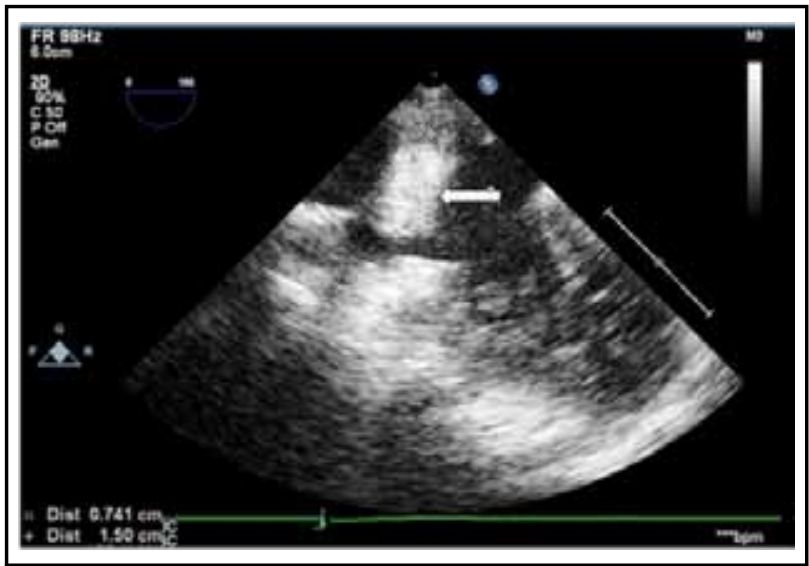

Figure 1. TEE showing a thrombus (arrow) in TCPC conduit detected on $5^{\text {th }}$ day after fenestration.

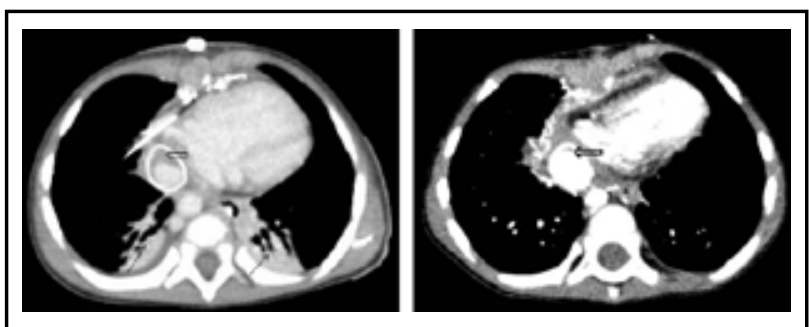

Figure 2. CECT showing thrombus in conduit 5 days after fenestration operation (large arrow), and bilateral pleural effusion (small arrows), (left); and regressed thrombus (arrow) in the conduit 2 weeks after intensive anticoagulation, (right).

\section{DISCUSSION}

Persistently elevated systemic venous pressure after Fontan operation often requires fenestration. Prophylactic fenestration at the time of primary operation has also been practiced by some institutions but it is not our institutional policy. Creation of fenestration is always at the expense of decreased $\mathrm{PaO} 2$, so our routine strategy is to perform the procedure on beating heart under cardiopulmonary bypass, extubate the patient in operating room for early recovery of pulmonary function, augment cardiac output with meticulous doses of inotropes and take a chance to see if the baby can tolerate the procedure without fenestration. Two most commonly practiced techniques of fenestration are direct side to side anastomosis between TCPC conduit and atrial wall, and use of small diameter PTFE graft to anastomose the TCPC conduit and atrium. Use of small diameter PTFE graft for fenestration makes it suitable for future catheter-based closure; however, this technique might offer inferior results as regards to thrombosis and occlusion of fenestration. ${ }^{7}$

Suitable candidates for Fontan are identified based on the preoperative catheterization reports and we pay due attention to PAI and Rp. Our patient had sufficient PAl implying adequate pulmonary vascular growth and borderline elevation of Rp. However, presence of $\mathrm{VV}$ collaterals between innominate vein and IVC (Figure 3) could have falsely lowered the actual value of $\mathrm{Rp}$. Our concern here is would the value of $\mathrm{Rp}$ go up if we had occluded these VV collaterals temporarily during pre-Fontan catheterization, thus predicting subsequent failure? Because thrombus was not detected at the time of fenestration, conduit thrombosis was not the cause of Fontan failure.

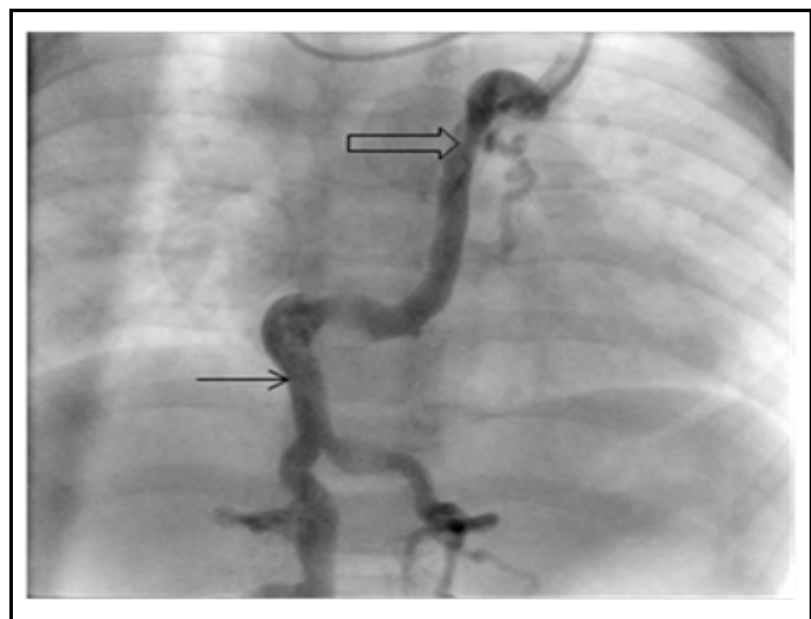

Figure 3. CECT VV collaterals between innominate vein (large arrow) and IVC (small arrow). 
Endothelial injury, turbulence/stasis of blood flow, use of artificial graft material, and inadequate anticoagulation contribute to thrombosis of the conduit. Risk of conduit thrombosis is significantly higher in patients with azygos continuation of IVC. ${ }^{8}$

In the absence of optimal guidelines for management of TCPC conduit thrombosis, surgical re-exploration and thrombectomy or conduit exchange is always an option; but it should be individualized to every patient weighing the risks/benefits. Combined treatment of thrombolysis followed by catheter intervention has also been described to treat thrombosis of extra- cardiac Fontan tunnel. ${ }^{9}$ In our view, this catheter technique poses the risk of thrombus migration with subsequent pulmonary and systemic embolization. Our patient was successfully managed conservatively with oral and intravenous anticoagulation although there was a genuine risk of pulmonary and/or systemic embolism due to presence of fenestration and single systemic ventricle. This management strategy came into effect after parents gave consent for conservative management out of the many options available. Her CVP at the time of transfer out from PICU was $13 \mathrm{mmHg}$; and during follow up after 4 months of surgery, parents report her acceptable quality of life with $\mathrm{SpO} 2$ ranging between $80-85 \%$ with home oxygen therapy.

\section{REFERENCES}

1. Anderson BW, Barron DJ, Jones TJ, Edwards L, Brawn W, Stumper O. Catheter takedown in the management of the acutely failing Fontan circulation. Ann ThoracSurg. 2011 Jul;92(1):346-8.

2. Rychik J, Goldberg D, Dodds K. Long-term results and consequences of single ventricle palliation. ProgPediatrCardiol. 2010 May;29(1):19-23.

3. Shirai LK, Rosenthal DN, Reitz BA, Robbins RC, Dubin AM. Arrhythmias and thromboembolic complications after the extracardiac Fontan operation. J Thorac Cardiovasc Surg. 1998 March;115(3):499-505.

4. Rosenthal DN, Friedman AH, Kleinman CS, Kopf GS, Rosenfeld LE, Hellenbrand WE. Thromboembolic complications after Fontan operations.Circulation. 1995;92:287-93.

5. Marrone C, Galasso G, Piccolo R, deLeva F, Paladini R, Piscione $\mathrm{F}$, et al. Antiplatelet versus anticoagulation therapy after extracardiac conduit Fontan: A systematic review and meta-analysis. Pediatr Cardiol. 2011 Jan;32(1):32-9.
6. Kim SJ, Kim WH, Lim HG, Lee JY. Outcome of 200 patients after an extracardiac Fontan procedure. J Thorac Cardiovasc Surg. 2008 Jul;136(1):108-16.

7. Kreutzer C, Schlichter AJ, Simon JL, Conejeros Parodi WM, Blunda C, Kreutzer GO. A new method for reliable fenestration in extracardiac conduit Fontan operations. Ann Thorac Surg. 2003 May;75(5):1657-9.

8. Konstantinov IE, Puga FJ, Alexi-Meskishvili VV. Thrombosis of intracardiac or extracardiac conduits after modified Fontan operation in patients with azygous continuation of the inferior vena cava. Ann Thorac Surg. 2001 Nov;72(5):1641-4.

9. Rauch R, Sieverding L, Hofbeck M. Thrombosis of an extracardiac Fontan tunnel: Combined treatment of thrombolysis and stenting. Catheter Cardiovasc Interv. 2009 Nov;74(6):917-9. 